\title{
Narrativas científicas sobre petróleo e mudancas do clima e suas reverberações na política climática brasileira
}

\section{José Eduardo Viglio* (1)}

\section{Gabriela Marques Di Giulio** (1)}

\author{
Fabiana Barbi* (1)
}

\section{Lúcia da Costa Ferreira*}

\section{Resumo}

De uma perspectiva analítica sobre as interações entre ciência e política em torno de questões energéticas e climáticas, o artigo identifica diferentes narrativas científicas referentes ao papel dos combustíveis fósseis, especificamente do petróleo do Pré-sal brasileiro, num contexto de mudança climática e transição para fontes renováveis de energia. Em seguida, analisa-se como estas narrativas se articularam com os posicionamentos do governo em dois momentos de inflexão nas negociações internacionais sobre o clima: na participação brasileira na COP-15, por meio da sua Política Nacional de Mudanças Climáticas (PNMC), estabelecida em 2009, e na COP-21, por meio da sua Contribuição Nacionalmente Determinada (iNDC na sigla em inglês), proposta em 2015. Por meio de pesquisa documental e entrevistas semiestruturadas, o artigo identifica e analisa três narrativas científicas sobre o Présal, moldadas tanto por elementos tanto factuais quanto subjetivos. Embora sejam consensuais em relação à mudança climática e suas causas humanas, evidenciam diferentes interpretações, expectativas e proposições em relação ao papel do petróleo, sobretudo em países com grandes reservas deste recurso, como é o caso brasileiro. Das três narrativas científicas, duas apresentaram maior proximidade e

* Universidade Estadual de Campinas, Campinas, SP, Brasil.

** Universidade de São Paulo, São Paulo, SP, Brasil. 
entrelaçamento com as decisões do governo brasileiro de proteger o Pré-sal de questionamentos e imposições climáticas e de concentrar as ações de mitigação, principalmente, no setor de uso e ocupação da terra. $\mathrm{O}$ artigo evidencia ainda a relevância da abordagem metodológica e analítica de narrativas científicas para compreender as interfaces entre ciência e política em torno de questões controversas e multifacetadas, como a mudança do clima.

Palavras chave: Mudança climática, Transição energética, Combustíveis fósseis, Política ambiental, Pré-sal.

\section{Scientific narratives about oil and climate change and their reverberations on Brazilian climate policy}

\section{Abstract}

From an analytical perspective on the interactions between science and policy around energy and climate issues, this paper identifies different scientific narratives regarding the role of fossil fuels, specifically Brazilian pre-salt oil, in a context of climate change and energy transition to renewable sources. Next, it analyzes how these narratives were articulated with the government's positions in two moments of inflection in the international climate negotiations: in the Brazilian participation in the COP-15, through its National Policy on Climate Change, established in 2009; and in COP-21, through its Intended Nationally Determined Contributions (iNDC), proposed in 2015. Using documentary research and semi-structured interviews, the article identifies and analyzes three scientific narratives about Pre-salt, shaped by both factual and subjective elements. Although all narratives are consensual about climate change and its human causes, they have brought different interpretations, expectations and propositions regarding the role of oil, especially in countries with large reserves of this resource, as is the Brazilian case. Of the three scientific narratives studied, two presented greater proximity and intertwining regarding the decisions of the Brazilian government in protecting the pre-salt from climate questions and impositions, and concentrating mitigation actions, especially in the sector of land use. The paper also highlights the relevance of the methodological and analytical approach to scientific narratives to understand the policy making process and the interfaces between science and policy around consted and multifaceted issues, such as climate change.

Keywords: Climate change, Energy transition, Fossil fuels, Environmental policy, Pre-salt. 


\section{Introdução}

complexidade da questão climática, com suas múltiplas causas $\triangle$ e consequências, tem possibilitado diferentes enquadramentos (frames) do fenômeno (Jang; Hart, 2015; Spence; Pidgeon, 2010; Nisbet, 2009). Apesar de um forte consenso científico (Cook et al. 2013), existem desacordos e resistências entre países, cientistas, indústrias, policymakers e organizações não governamentais (ONGs) em relação ao enfrentamento do aquecimento global (Ostrom, 2012; Anderson, 2009). Os frames relacionados aos efeitos e possíveis soluções do problema têm sido empregados estrategicamente por diversos atores, em um esforço de moldar a opinião pública e o processo decisório (Singh; Swanson, 2017; Hannigan, 2014).

As posições e interesses do goveno brasileiro nos debates multilaterais sobre mudança climática, por exemplo, têm sido marcados por considerações de ordem de soberania, segurança e defesa do seu crescimento econômico. O governo brasileiro liderou as nações em desenvolvimento nos debates sobre o clima exigindo ações incisivas dos países industrializados, ao mesmo tempo em que definiu metas claras, mas voluntárias, para reduzir emissões de gases do efeito estufa (GEE) no Brasil (Vieira; Dalgaard, 2013).

Entre as metas propostas feitas pelo Brasil no âmbito do Acordo de Paris firmado em 2015, por exemplo, estão a redução de emissões em 37\% (GWP-100) em 2025, em relação aos níveis de 2005, e a possibilidade de redução de até 43\% (GWP-100) em 2030. Para isso, o governo se comprometeu com o aumento do uso de energias renováveis na matriz energética e em zerar o desmatamento ilegal na região amazônica, além de adotar medidas de restauração e reflorestamento em todo o território (Itamaraty, 2015).

Ao mesmo tempo, o Brasil aspira tornar-se um dos maiores produtores de petróleo com as reservas offshore do Pré-sal ${ }^{1}$, estimadas entre 119-176 bilhões de barris (Lefèvre; Wills; Hourcade, 2018). As emissões de GEE baseadas em 176 bilhões de barris corresponderiam, segundo estimativas, a $18 \%$ de todo o carbono que a humanidade poderia emitir até 2100, para manter o aquecimento do planeta abaixo de 1,5oC (Matsuura, 2017).

${ }^{1} \mathrm{O}$ petróleo está localizado numa distância que pode chegar a $300 \mathrm{~km}$ da costa e abaixo d lâmina d'água e de uma camada de sal que pode alcançar 7000 metros de profundidade. A província do Pré-sal coloca o Brasil entre os países com maiores reservas de petróleo e gás do mundo (Todd; Carvalho, 2016; Jones; Chaves, 2015). 
Com foco analítico nas interações entre ciência e política em torno de questões energéticas e climáticas, esse artigo identificou diferentes interpretações e enquadramentos (frames) estabelecidos por cientistas brasileiros sobre o papel do petróleo, especificamente das reservas do Pré-sal, num contexto de mudança climática. Em seguida analisaram-se as reverberações dessas interpretações nas decisões do governo federal, em dois momentos de inflexão nas negociações internacionais sobre o clima: na participação brasileira na COP-15, por meio da sua Política Nacional de Mudanças Climáticas (PNMC), estabelecida em 2009, e na COP-21, por meio da sua Contribuição Nacionalmente Determinada (iNDC), proposta em 2015. Neste artigo, estas interpretações são compreendidas como narrativas científicas, ou seja, explanações oferecidas por cientistas com base no conhecimento científico disponível e a partir de suas visões, interpretações e valores particulares, que contêm elementos descritivos e prescritivos sobre determinado problema com possíveis implicações políticas (Keller, 2009). A abordagem adotada ancora-se em diferentes contribuições da ciência política (Keller, 2009; Stone, 1989; 1997), da sociologia ambiental (Hannigan, 2014) e dos estudos sociais em ciência e tecnologia (Jasanoff; Wynne, 1998; Monteiro, 2012).

Neste artigo, as narrativas científicas sobre o Pré-sal e mudança climática foram tratadas como elementos de potencial influência e reverberação nas políticas climáticas brasileiras. Três narrativas científicas emergem do conjunto de materiais analisado (incluindo jornais, artigos, leis, documentos governamentais, conteúdos midiáticos e entrevistas com pesquisadores): i) o Pré-sal como agravante da mudança climática (identificada como Narrativa A); ii) o Pré-sal como eixo do desenvolvimento nacional (Narrativa B); e iii) o Pré-sal como fomentador da transição energética para fontes de baixo carbono (Narrativa C). Os resultados aqui apresentados e discutidos mostram como elementos factuais e valorativos são articulados nas narrativas científicas sobre o Pré-sal e, ao mesmo tempo, destacam as imbricações destas narrativas com as decisões do governo de proteger a expansão de petróleo no país, com o Pré-sal, tanto na Política Nacional de Mudanças Climáticas (PNMC) quanto na Contribuição Nacionalmente Determinada (iNDC), proposta pelo Brasil na COP-21 em 2015. 


\section{Referencial teórico e metodológico}

\section{Narrativas científicas e policy making}

Narrativas, no sentido mais amplo, são definidas como histórias simples que descrevem um problema e suas causas, mostram suas consequências e sugerem soluções (Roe, 1994). Mais recentemente, as narrativas têm sido adotadas em estudos que enfocam interpretação, argumentação e justificação por parte dos cientistas (Forrester, 2017; Currie; Sterelny, 2017; Morgan; Wise, 2017; Beatty, 2017). Por narrativa da ciência entende-se aquela que é estabelecida e reforçada por cientistas ou atores que reivindicam a participação na comunidade científica (Keller, 2009).

A narrativa, entendida como uma categoria particular de comunicação e um método de organização cognitiva (Herman, 2009), é tratada como um instrumento relevante na comunicação da ciência e na explicação de fenômenos complexos (Downs, 2014). Para Dahlstrom (2014), a apresentação de achados científicos por meio de narrativas torna tais fenômenos mais acessíveis, intuitivos e memoráveis. Particularmente para questões ambientais, Hannigan (2014) argumenta que os cientistas elaboram determinados discursos para dar voz a suas questões e às reivindicações ambientais. Nessa estratégia, valem-se de argumentações cognitivas, sociais, materiais e interpretativas para enquadrar uma questão. Contudo, as escolhas realizadas sobre como contar a história, ao mesmo tempo que destacam, ocultam certos aspectos dos fenômenos (Gabriel, 2004).

As narrativas científicas contêm tanto elementos descritivos quanto prescritivos, e possibilitam interpretações, avaliações e soluções particulares para um problema (Entman, 2004; Von Meier; Miller; Keller, 1998). Ao combinar elementos factuais e normativos, cruzam a fronteira entre ciência e política (Jasanoff; Wynne, 1998), embora sejam, frequentemente, apresentadas como se fossem inteiramente factuais, apoiando-se na autoridade da ciência para sustentarem um dado enquadramento (van Bommel; van der Zouwen, 2012; Keller, 2009; Stone, 1989).

$\mathrm{Na}$ análise sobre processo político, Stone (1997) argumenta que a narrativa científica é compreendida como um instrumento para integração de ideias, direcionando a conceituação de um problema político. Nesse processo, a narrativa científica compete com outras narrativas. A autora identifica dois enredos principais que, em geral, moldam as narrativas, sejam 
científicas ou outras: (i) uma história de declínio, em que um estado de coisas anteriomente bem sucedido está se perdendo; e (ii) uma história de controle, em que um estado tolerado, mas não desejado, pode ser aliviado por meio de novas ações em curso (Keller, 2009; Stone, 1997).

Para conseguir estabilidade e ganhar status de problema na agenda política, é importante que uma narrativa tenha a capacidade de retratar um problema como solúvel (Keller, 2009; Lawton, 2007). Keller (2009), por exemplo, ao analisar as narrativas científicas sobre chuva ácida e mudança climática nos Estados Unidos, argumenta que uma narrativa ganha estabilidade por meio de arranjos institucionais que crescem em resposta a ela. Tais arranjos consolidam a narrativa na medida em que as atividades institucionais reproduzem e reforçam uma visão particular de uma questão (Keller, 2009; Hannigan, 2014; Hajer; Hoppe; Jennings, 1993). Para conseguir estabilidade as narrativas devem contar com dispositivos retóricos e enredos familiares e apoiar-se em valores ou crenças profundamente arraigadas (Keller, 2009).

Hermwille (2016), em estudos sobre sociedades em transição, discute como as narrativas podem influenciar processos decisórios e como ajudam a delimitar o espaço do que é politicamente viável, contribuindo assim para a inércia dos regimes no que diz respeito à mudança sociotécnica. Em temas controversos como o da mudança climática, envolvendo multi-atores, as narrativas são mais ou menos aceitas pelos atores políticos dependendo da extensão com que concordam com suas crenças compartilhadas e motivações políticas (Lawton; Rudd, 2014; Shanahan; Jones; McBeth, 2011; Jenkins-Smith; Sabatier, 1993).

A revisão de literatura sobre narrativas, em particular a científica, evidencia que suas análises no processo político iluminam também os argumentos em jogo, os conceitos e os enquadramentos dados na elaboração e implementação de políticas públicas. Nessa perspectiva, estudos sobre narrativas científicas trazem importantes contribuições para a abordagem analítica de arenas, particularmente para compreender como cientistas e discursos científicos são estabelecidos e mobilizados para influenciar decisões políticas. A noção de arena remete: i) ao locus ou espaço social de interação e construção dos problemas sociais (Hilgartner; Bosk, 1988); ii) a uma metáfora para descrever a localização simbólica de ações políticas que influenciam decisões coletivas (Renn, 1992); iii) a um political establishment no qual os atores dirigem suas exigências àqueles que são responsáveis 
pela tomada de decisão, na esperança de influenciar o processo decisório (Hannigan, 2014); e iv) a um sistema de relações que influencia e dirige a formulação e implementação de políticas públicas (Ferreira, 2004; 2012; Ferreira et al., 2017).

\section{Procedimentos de pesquisa: levantamento e análise de dados}

Esse trabalho identificou e analisou as narrativas científicas sobre o Pré-sal e mudança climática e suas possíveis reverberações nas decisões, a partir de pesquisa qualitativa, descritiva e interpretativa. Os procedimentos e instrumentos de pesquisa utilizados consistem em pesquisa documental, realização de entrevistas e análise de conteúdo.

\section{Pesquisa documental}

A pesquisa documental incluiu análise: i) de textos publicados nos jornais Folha de S. Paulo e O Globo entre 2007 e 2016; ii) de artigos científicos levantados nas bases Google Acadêmico, Scielo, Scopus e base multidisciplinar da Elsevier; iii) da Política Nacional de Mudanças Climáticas (PNMC) (Lei n. 12.1874); e iv) da iNDC brasileira apresentada e aprovada na COP-21em Paris.

Para identificar e analisar os debates protagonizados e reverberados no palco midiático, os jornais selecionados, além de sua importância em termos de tiragem e circulação, estão sediados nos dois estados da federação de maior impacto econômico do Pré-sal, São Paulo e Rio de Janeiro. O recorte temporal adotado na pesquisa documental desses dois jornais correspondeu ao período de janeiro de 2007 a dezembro 2016, que engloba o anúncio da descoberta, o início da produção dessas reservas e a realização da COP 21 em Paris. Para a consulta nos acervos destes jornais foram utilizadas as seguintes palavras-chaves: pré-sal - meio ambiente; pré-sal - mudança climática; pré-sal - transição energética. Foram identificados e analisados ao todo 30 textos, distribuídos em: linha editorial, opinião, reportagem e carta de leitores. Já a busca complementar com artigos científicos foi realizada a partir da utilização dos seguintes descritores em português e em inglês em associação com pré-sal (pre-salt): mudança climática (climate change), impactos ambientais (environmental impacts), transição energética (energy transition) e Brasil (Brazil). Cabe destacar que não foi objeto da 
pesquisa a realização de uma revisão sistematizada da literatura científica a partir desses descritores. O levantamento nessas bases teve apenas o objetivo de confrontar o conteúdo obtido nas entrevistas realizadas e nos documentos analisados.

\section{ENTREVISTAS}

A análise inicial dos textos publicados nos dois jornais permitiu a identificação de um grupo de cientistas que atuam em questões climáticas e energéticas no Brasil. Desse grupo, nove cientistas foram entrevistados. A seleção para a realização das entrevistas semiestruturadas levou em conta os seguintes aspectos: (i) visibilidade midiática nacional dos pesquisadores; (ii) posturas públicas diferentes sobre questões climáticas e energéticas; (iii) envolvimento em atividades de pesquisa e ensino em instituições brasileiras; e (iv) resposta positiva à solicitação de entrevista, quando da realização da pesquisa empírica. Estas entrevistas possibilitaram a obtenção de informações sobre conteúdos divulgados acerca dos temas tratados em outras mídias, ampliando, assim, os documentos analisados nesse artigo para além dos dois jornais selecionados. Esses conteúdos também foram analisados, permitindo a identificação de narrativas de 20 cientistas brasileiros.

\section{ANÁLISE}

De uma perspectiva analítica que privilegia múltiplos textos (orais e escritos) para análise de narrativas (Keats, 2009), e considerando que a heterogeneidade de materiais acessados permite maior consistência na identificação das narrativas científicas, o artigo estrutura-se em dados provindos de jornais, artigos, leis, documentos governamentais, conteúdos midiáticos e entrevistas. Esse conjunto de materiais foi analisado a partir da técnica de análise de conteúdo, cujas finalidades são a descrição objetiva, sistemática e qualitativa do conteúdo manifesto (Bardin, 1977); e de análise de narrativas (Stone, 1989; 1997; Keller, 2009) para identificação de histórias causais, enunciados descritivos e prescritivos, problemas e soluções, culpados e vítimas.

O conjunto de informações recolhidas e analisadas foi confrontado com a literatura sobre mudança climática e transição energética e permitiu a identificação de três narrativas científicas sobre o Pré-sal e mudança 
climática no Brasil. A análise dessas narrativas explora como seus argumentos, ideias e frames se articulam com os posicionamentos do governo nos dois momentos que interessam a esse artigo: COP-15, por meio da Política Nacional de Mudanças Climáticas (PNMC), estabelecida em 2009; e COP21, por meio da sua Intended Nationally Determined Contributions (iNDC), proposta em 2015. A análise buscou compreender, especialmente, como as narrativas científicas identificadas se aproximam e se distanciam das decisões do governo brasileiro. A figura 1 traz uma representação gráfica da metodologia adotada na pesquisa.

Figura 1. Representação metodológica da pesquisa

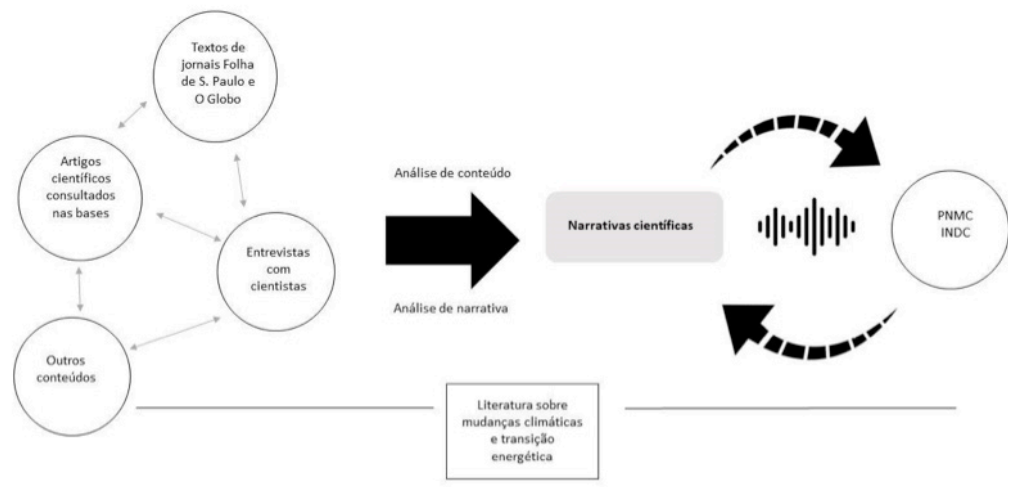

Fonte: Elaboração dos autores.

\section{Resultados e discussão}

\section{Narrativas científicas sobre o Pré-sal, mudança climática e} transição energética no Brasil

O perfil dos cientistas, cujas narrativas são analisadas neste trabalho, é descrito no Quadro 1. Nele sinalizam-se também aqueles que foram entrevistados no âmbito da pesquisa realizada. 
Quadro 1. Características dos cientistas e suas narrativas sobre o Pré-sal

\begin{tabular}{|c|c|c|c|c|c|c|c|}
\hline & Formação & Instituição & Área de atuação & 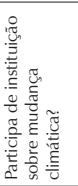 & $\begin{array}{l}\text { Onde expressou } \\
\text { sua posição? }\end{array}$ & 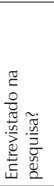 & 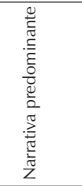 \\
\hline 1 & $\begin{array}{l}\text { Sociologia, } \\
\text { Economia, } \\
\text { Demografia. }\end{array}$ & $\mathrm{IBGE}^{1}$ & $\begin{array}{l}\text { Dinâmica populacional, políticas } \\
\text { públicas e desenvolvimento } \\
\text { sustentável }\end{array}$ & Não & Revistas e blogs & Sim & $\begin{array}{l}\text { Narrativa } \\
\text { A }\end{array}$ \\
\hline 2 & $\begin{array}{l}\text { Filosofia, } \\
\text { Ciência Política, } \\
\text { Economia }\end{array}$ & $\mathrm{USP}^{2}$ & $\begin{array}{l}\text { Economia, desenvolvimento } \\
\text { sustentável e impactos } \\
\text { socioeconômicos das mudanças } \\
\text { climáticas }\end{array}$ & $\mathrm{PBMC}^{12}$ & Jornais & Não & $\begin{array}{l}\text { Narrativa } \\
\text { A }\end{array}$ \\
\hline 3 & $\begin{array}{l}\text { Engenharia } \\
\text { Eletrônica, } \\
\text { Computação } \\
\text { Aplicada }\end{array}$ & $\mathrm{INPE}^{3}$ & $\begin{array}{l}\text { Geoinformática, modelagem } \\
\text { ambiental, análise espacial, } \\
\text { bancos de dados geográficos, } \\
\text { processamento de imagens de } \\
\text { sensores remotos }\end{array}$ & Não & $\begin{array}{l}\text { Revista de } \\
\text { divulgação } \\
\text { cientîica }\end{array}$ & Não & $\begin{array}{l}\text { Narrativa } \\
\text { A }\end{array}$ \\
\hline 4 & $\begin{array}{l}\text { Engenharia } \\
\text { Eletrônica e } \\
\text { Física }\end{array}$ & UNICAMP $^{4}$ & $\begin{array}{l}\text { Ciências Exatas e da Terra, Física da } \\
\text { Matéria Condensada }\end{array}$ & Não & $\begin{array}{l}\text { Jornal Folha de S. } \\
\text { Paulo }\end{array}$ & Não & $\begin{array}{l}\text { Narrativa } \\
\text { A }\end{array}$ \\
\hline 5 & $\begin{array}{l}\text { Física, Ciências } \\
\text { Atmosféricas }\end{array}$ & $\mathrm{UECE}^{5}$ & $\begin{array}{l}\text { Microfísica e macrofísica de } \\
\text { nuvens, modelagem atmosférica, } \\
\text { climatologia, mudanças climáticas e } \\
\text { meteorologia aplicada }\end{array}$ & PBMC & $\begin{array}{l}\text { Jornais, revistas, } \\
\text { blogs }\end{array}$ & Sim & $\begin{array}{l}\text { Narrativa } \\
\text { A }\end{array}$ \\
\hline 6 & $\begin{array}{l}\text { Engenharia } \\
\text { Eletrônica, } \\
\text { Meteorologia }\end{array}$ & INPE & $\begin{array}{l}\text { Meteorologia, climatologia, } \\
\text { modelagem climática e ciếncia do } \\
\text { sistema terrestre }\end{array}$ & $\begin{array}{l}\text { IPCC }^{13} \\
\text { PBMC' } \\
\text { e Rede } \\
\text { Clima }\end{array}$ & $\begin{array}{l}\text { Audiência Pública, } \\
\text { Congresso } \\
\text { Nacional e Jornais }\end{array}$ & Não & $\begin{array}{l}\text { Narrativa } \\
\text { B }\end{array}$ \\
\hline 7 & $\begin{array}{l}\text { Sociologia, } \\
\text { Relações } \\
\text { Internacionais }\end{array}$ & $\mathrm{UFABC}^{6}$ & $\begin{array}{l}\text { Economia, política internacional, } \\
\text { geopolítica da energia, China, } \\
\text { política externa brasileira, } \\
\text { integração e economia brasileira } \\
\text { contemporânea. }\end{array}$ & Não & $\begin{array}{l}\text { Artigo científico e } \\
\text { revistas }\end{array}$ & Não & $\begin{array}{l}\text { Narrativa } \\
\text { B }\end{array}$ \\
\hline 8 & $\begin{array}{l}\text { Biologia } \\
\text { Molecular }\end{array}$ & $\begin{array}{l}\text { UNIFESP } \\
\text { SBPC }^{7} \mathrm{e}\end{array}$ & Glicoquímica e glicobiologia & Não & $\begin{array}{l}\text { Jornais, revistas e } \\
\text { site de notícias }\end{array}$ & Não & $\begin{array}{l}\text { Narrativa } \\
\text { B }\end{array}$ \\
\hline 9 & $\begin{array}{l}\text { Jornalismo, } \\
\text { Relações } \\
\text { Internacionais, } \\
\text { Ciência Política }\end{array}$ & UFABC & $\begin{array}{l}\text { Energia e relações internacionais, } \\
\text { geopolítica do petróleo }\end{array}$ & Não & $\begin{array}{l}\text { Sites de notícias } \\
\text { e blogs }\end{array}$ & Não & $\begin{array}{l}\text { Narrativa } \\
\text { B }\end{array}$ \\
\hline 10 & $\begin{array}{l}\text { Engenharia } \\
\text { Civil, } \\
\text { Engenharia } \\
\text { Nuclear e } \\
\text { Planejamento } \\
\text { Energético }\end{array}$ & USP & $\begin{array}{l}\text { Planejamento energético, modelos } \\
\text { de demanda e recursos e oferta de } \\
\text { energia, uso racional de energia }\end{array}$ & Não & $\begin{array}{l}\text { Jornais, sites de } \\
\text { notícia, livros, } \\
\text { artigo científico }\end{array}$ & Sim & $\begin{array}{l}\text { Narrativa } \\
\text { B }\end{array}$ \\
\hline 11 & $\begin{array}{l}\text { Engenharia } \\
\text { Elêtrica, } \\
\text { Economia, } \\
\text { Engenharia de } \\
\text { Sistemas }\end{array}$ & UFRJ ${ }^{9}$ & $\begin{array}{l}\text { Energia e meio ambiente, } \\
\text { planejamento energético, } \\
\text { planejamento ambiental, } \\
\text { desenvolvimento sustentável e } \\
\text { mudanças climáticas }\end{array}$ & $\begin{array}{l}\text { IPCC, } \\
\text { PBMC, }^{\prime} \\
\text { FBMC }^{14}\end{array}$ & $\begin{array}{l}\text { Jornal, sites de } \\
\text { notícias e Relatório } \\
\text { do PBMC }\end{array}$ & Sim & $\begin{array}{l}\text { Não } \\
\text { afiliação a } \\
\text { nenhuma } \\
\text { das três } \\
\text { narrativas }\end{array}$ \\
\hline 12 & $\begin{array}{l}\text { Engenharia } \\
\text { Mecânica, } \\
\text { Planejamento } \\
\text { Energético, } \\
\text { Engenharia de } \\
\text { Produção }\end{array}$ & UFRJ & $\begin{array}{l}\text { Planejamento de transporte, } \\
\text { mobilidade sustentável, energia } \\
\text { renovável, mudança climática e } \\
\text { cidades e meio ambiente }\end{array}$ & $\begin{array}{l}\text { IPCC } \\
\text { PBMC }\end{array}$ & $\begin{array}{l}\text { Jornal, sites de } \\
\text { notícias e blogs }\end{array}$ & Sim & $\begin{array}{l}\text { Narrativa } \\
\mathrm{C}\end{array}$ \\
\hline 13 & $\begin{array}{l}\text { Física, Ciências } \\
\text { Físicas }\end{array}$ & USP & $\begin{array}{l}\text { Física nuclear, energia, } \\
\text { planejamento energético e biomassa }\end{array}$ & IPCC & $\begin{array}{l}\text { Jornal, artigo } \\
\text { científico }\end{array}$ & Sim & $\begin{array}{l}\text { Narrativa } \\
\mathrm{C}\end{array}$ \\
\hline
\end{tabular}


(cont.)

\begin{tabular}{|c|c|c|c|c|c|c|c|}
\hline 14 & $\begin{array}{l}\text { Geólogo, } \\
\text { Doutor em } \\
\text { Geociências }\end{array}$ & UNESP $^{10}$ & $\begin{array}{l}\text { Petrologia sedimentar de rochas } \\
\text { carbonaticas, paleoecologia de } \\
\text { microorganismos marinhos }\end{array}$ & Não & Jornal & Não & $\begin{array}{l}\text { Narrativa } \\
\text { C }\end{array}$ \\
\hline 15 & $\begin{array}{l}\text { Física, } \\
\text { Engenharia } \\
\text { Nuclear, } \\
\text { Doutor em } \\
\text { Física }\end{array}$ & UFRJ & $\begin{array}{l}\text { Planejamento energético, mudanças } \\
\text { climáticas e epistemologia e história } \\
\text { da ciência }\end{array}$ & $\begin{array}{l}\text { FBMC, } \\
\text { IPCC }\end{array}$ & $\begin{array}{l}\text { Jornais, audiência, } \\
\text { Congresso } \\
\text { Nacional. }\end{array}$ & Sim & $\begin{array}{l}\text { Narrativa } \\
\mathrm{C}\end{array}$ \\
\hline 16 & $\begin{array}{l}\text { Engenharia } \\
\text { Química e } \\
\text { Planejamento } \\
\text { Energético }\end{array}$ & UFRJ & $\begin{array}{l}\text { Eficiência energética, matriz } \\
\text { energética, cogeração, } \\
\text { biocombustíveis, refino de mercado } \\
\text { e mercado de petróleo e derivados } \\
\text { tecnologia CCS }\end{array}$ & PBMC & $\begin{array}{l}\text { sites de notícias, } \\
\text { jornais, artigos }\end{array}$ & Não & $\begin{array}{l}\text { Narrativa } \\
\mathrm{C}\end{array}$ \\
\hline 17 & $\begin{array}{l}\text { Engenharia } \\
\text { de Minas, } \\
\text { Engenharia } \\
\text { Mineral, } \\
\text { Engenharia de } \\
\text { Petróleo }\end{array}$ & USP & $\begin{array}{l}\text { Engenharia de Minas, com ênfase } \\
\text { em exploraçãao e produçãao } \\
\text { de petróleo, engenharia de } \\
\text { reservatórios de petróleo }\end{array}$ & Não & $\begin{array}{l}\text { Jornal da ciência e } \\
\text { outros jornais }\end{array}$ & Não & $\begin{array}{l}\text { Narrativa } \\
\mathrm{C}\end{array}$ \\
\hline 18 & $\begin{array}{l}\text { Engenharia } \\
\text { Eletrica, } \\
\text { Planejamento } \\
\text { Energético }\end{array}$ & UFRJ & $\begin{array}{l}\text { Planejamento energético e } \\
\text { mudanças climáticas. }\end{array}$ & $\begin{array}{l}\text { IPCC e } \\
\text { PBMC }\end{array}$ & $\begin{array}{l}\text { Jornais, rádio, } \\
\text { revistas e artigo } \\
\text { científico }\end{array}$ & Sim & $\begin{array}{l}\text { Narrativa } \\
\text { C }\end{array}$ \\
\hline 19 & $\begin{array}{l}\text { Ciências } \\
\text { Econômicas, } \\
\text { Economia } \\
\text { Industrial } \\
\text { Economia } \\
\text { Aplicada }\end{array}$ & UFRJ & $\begin{array}{l}\text { Organização industrial e dinâmica } \\
\text { das indústrias de energia, regulação } \\
\text { e políticas energéticas e inovaçâo }\end{array}$ & Não & $\begin{array}{l}\text { Blogs da área de } \\
\text { petróleo e energia }\end{array}$ & Não & $\begin{array}{l}\text { Narrativa } \\
\text { C }\end{array}$ \\
\hline 20 & $\begin{array}{l}\text { Ciências } \\
\text { Econômicas }\end{array}$ & PUC-RJ'11 & $\begin{array}{l}\text { Economia, com ênfase em história } \\
\text { econômica do Brasil, economia do } \\
\text { meio ambiente, desénvolvimento } \\
\text { econômico sustentável, história do } \\
\text { aquecimento global }\end{array}$ & Não & $\begin{array}{l}\text { Jornais e site de } \\
\text { notícias }\end{array}$ & Não & $\begin{array}{l}\text { Narrativa } \\
\mathrm{C}\end{array}$ \\
\hline
\end{tabular}

Siglas: ${ }^{1}$ Instituto Brasileiro de Geografia e Estatística; ${ }^{2}$ Universidade de São Paulo; ${ }^{3}$ Instituto Nacional de Pesquisas Espaciais; ${ }^{4}$ Universidade Estadual de Campinas; ${ }^{5}$ Universidade Estadual do Ceará; ${ }^{6}$ Universidade Federal do ABC; ${ }^{7}$ Universidade Federal de São Paulo; ${ }^{8}$ Sociedade Brasileira para o Progresso da Ciência; ${ }^{9}$ Universidade Federal do Rio de Janeiro; ${ }^{10}$ Universidade Estadual Paulista; ${ }^{11}$ Pontifícia Universidade Católica do Rio de Janeiro; ${ }^{12}$ Painel Brasileiro de Mudança Climática; ${ }^{13}$ International Panel on Climate Change; ${ }^{14}$ Fórum Brasileiro de Mudança Climática.

Fonte: Elaboração dos autores.

\section{Narrativa A: o Pré-sal como agravante da mudança climática}

Para esta narrativa, o Pré-sal, em função do seu volume, é um agravante da mudança climática, pois há um entendimento entre os cientistas de que a exploração das últimas reservas fósseis, que inclui o Pré-sal brasileiro, é incompatível com qualquer perspectiva de manter o sistema climático sob limites seguros. Para esses cientistas, o Pré-sal e outras reservas lançarão 
uma quantidade de $\mathrm{CO} 2$ que extrapolará substancialmente o marco de 450 ppm de CO2 na atmosfera, marco considerado em alguns estudos como um tipping point para a estabilidade/manutenção dos sistemas ecológicos (McNeil; Matear, 2008; Hoegh-Guldberg et al., 2007). Segundo o cientista 5, o Pré-sal é especialmente problemático, pois "A quantidade de carbono armazenada nas reservas fósseis (incluindo o Pré-sal) é da ordem de 2,8 trilhões de toneladas métricas, o que é no mínimo cinco vezes mais do que supostamente seria permitido queimar" (Cientista 5, trecho citado em texto de blog pessoal em 2013).

Nessa perspectiva, a queima do petróleo do Pré-sal contribuiria para consumir e ultrapassar o orçamento de carbono remanescente (Geels, 2014), aumentando a sensibilidade climática ${ }^{2}$ do planeta. Nas palavras do cientista 5, "A exploração e queima dessa matéria-prima colocam o Brasil, também, na engrenagem global de mudanças climáticas" (trecho de texto divulgado na Agência Universitária de Notícias, 2018). Os cientistas desta narrativa evocam a imagem de um sistema próximo do colapso e apontam a necessidade de ações preventivas envolvendo a diminuição ou a não utilização dessas reservas petrolíferas, bem como a reversão dos investimentos energéticos em fontes renováveis. Esta é a posição do cientista 1, quando questiona se "não seria melhor utilizar todos estes recursos que vão ser aplicados no Pré-sal para investir em equipamentos e tecnologia de energia verde, renovável e de baixo-carbono" (Cientista 1, trecho de texto divulgado no Portal Ecodebate em 2010).

Esse sentido de urgência na redução das emissões está em consonância com estudos recentes como o de Raftery e colaboradores (2017), que apontam para a necessidade de diminuição das emissões mais rapidamente do que no passado recente para se atingir a meta de $1,5-2^{\circ} \mathrm{C}$ de aquecimento até 2100 . Para esses autores, há apenas $5 \%$ de probabilidade de se manter o aquecimento global, até o fim do século, dentro de um limite de $2^{\circ} \mathrm{C}$. Para isso, segundo McGlade e Ekins (2015), um terço das reservas de petróleo, a metade das de gás e mais de $80 \%$ das de carvão devem permanecer não utilizadas entre 2010-2050.

Além de o setor fóssil se configurar como um dos principais responsáveis pelo aquecimento do planeta, este também é tratado nessa narrativa como

${ }^{2} \mathrm{~A}$ sensibilidade climática pode ser entendida como o grau de aquecimento associado a uma duplicação da concentração de $\mathrm{CO} 2$ atmosférico em relação aos níveis observados antes da Revolução Industrial, que era de 275 ppm (Previdi et al., 2013). 
um vilão e como força contrária às ações de mitigação, devido aos recursos de poder de ordem instrumental, discursiva, institucional e econômica de que dispõe (Geels, 2014). Para o cientista 5, "A indústria de combustíveis fósseis se constitui hoje em dia no núcleo central do capitalismo global. É a essas corporações, destrutivas em sua essência, que interessa a extração dos combustíveis fósseis até a última pedra de carvão e gota de óleo via fratura, dentre outras" (Cientista 5, trecho citado em texto de blog pessoal em 2013). Essa também é a perspectiva do cientista 2: "Como a decisão referente a esses investimentos não é tomada levando em conta seus efeitos globais, cada país, cada empresa dá as costas aos evidentes impactos destrutivos desses projetos" (Cientista 2, trecho de texto divulgado na Folha de S. Paulo em 2013). Segundo ainda o cientista 4, a única explicação para a continuidade de investimentos no Pré-sal "é a concentração de poder político que a exploração de petróleo proporciona em um monopólio de fato na mão do Estado" (Cientista 4, trecho de texto divulgado na Folha de S. Paulo em 2009).

Essa narrativa também traz e reforça o conceito de "carbon lock in" (Seto et al., 2016; Unruh, 2000) na sua crítica aos investimentos no Pré-sal. Este conceito descreve a interdependência em relação aos combustíveis fósseis por meio de um processo de co-evolução institucional e tecnológica que inibe a difusão de fontes de baixo carbono, apesar de possíveis vantagens ambientais e econômicas (Unruh, 2000). Para o cientista 4, com a exploração do Pré-sal, "negligencia o governo a ampliação da produção do etanol, cuja tecnologia já está desenvolvida, priorizando a promessa incerta do pré-sal. E isso apesar do potencial de produção maior, de investimentos menores para a mesma produção de energia e da sustentabilidade desse biocombustível" (Cientista 4, trecho de texto divulgado na Folha de S. Paulo em 2009). Do mesmo modo, para o cientista 2, os investimentos no Pré-sal "trazem o inevitável inconveniente de fortalecer as estruturas materiais e institucionais da economia baseada em combustíveis fósseis" (Cientista 2, trecho de texto divulgado na Folha de S. Paulo em 2012).

Essa narrativa questiona a visão do Pré-sal como um fator de redenção social e eixo condutor do desenvolvimento nacional, narrativa que será analisada a seguir. Para os cientistas da Narrativa A, há uma evidente contradição nessa perspectiva desenvolvimentista do Pré-sal brasileiro. Essa é a posição, por exemplo, do cientista 2, que nomeou tal visão como 
"um mito do veneno que salva" (Cientista 2, trecho de texto divulgado na Folha de S. Paulo em 2013).

Nessa mesma linha, para o cientista 3, "o Brasil terá de rever a ideia de que a exploração de petróleo da camada Pré-sal irá redimir a economia brasileira". Para ele, "não é possível estar na coalizão de altas ambições (descarbonização) e, ao mesmo tempo, cogitar vender 6 milhões de barris de petróleo por dia" (Cientista 3, trecho de texto publicado na Revista Pesquisa Fapesp em 2016).

\section{Narrativa B: o Pré-sal como eixo do desenvolvimento nacional}

Os cientistas desta narrativa reconhecem a relação entre combustíveis fósseis e aquecimento do planeta. Contudo, questionam e relativizam a contribuição do Pré-sal para o problema e destacam seus potenciais benefícios sociais e econômicos. Essa narrativa enquadra o petróleo do Présal, principalmente, como oportunidade econômica e social, e não como ameaça climática. Ela ressalta o caráter estratégico dessas reservas para a inserção internacional brasileira na geopolítica do petróleo e na retomada de crescimento econômico (Heidrich; Haslam, 2016). Por exemplo, na perspectiva do cientista 9, "a causa das mudanças climáticas não é a extração de combustíveis fósseis, e sim, o consumo concentrado, principalmente, nos países industrializados [...] a proporção a ser fornecida pelo Brasil ao mercado global de petróleo no auge da produção do Pré-sal equivalerá a uma ínfima parcela do total" (Cientista 9, trecho de texto divulgado no Brasil de Fato em 2014).

Essa narrativa destaca o tema da equidade no enfrentamento da mudança climática. Portanto, ao justificar e defender o Pré-sal, ela acentua a questão das emissões desiguais ${ }^{3}$ entre os países, a responsabilidade histórica diferenciada entre eles, e a necessidade de preservação das oportunidades de crescimento econômico dos países em desenvolvimento, como o Brasil (Klinsky et al., 2017). Para esses cientistas, os maiores vilões do aquecimento global são os países desenvolvidos, notadamente os Estados Unidos: "nunca se propôs a redução da oferta de petróleo como política

${ }^{3}$ Segundo Althor, Watson e Fuller (2016) emissões de gases de efeito estufa estão distribuídas de forma muito desigual nos países do mundo, com os dez principais países emissores de GEE gerando mais que $60 \%$ do total de emissões e três países, China $(21,1 \%)$, Estados Unidos da América (14,1\%) e a Índia (5,2\%) são de longe os maiores contribuintes. 
ambiental. Mesmo nesse caso, não parece justo que a conta do sacrifício seja paga pela periferia do mundo. Se é para deixar o óleo embaixo da terra, por que não começar pelos Estados Unidos?" (Cientista 9, trecho de texto divulgado no Brasil de Fato em 2014).

Além disso, para o cientista 10, qualquer decisão acerca de restrições na produção e consumo deve ser tomada numa escala global, e não no nível de um país. Para ele, dada a dinâmica global do petróleo, se um país se restringir na produção, outro vai ocupar o seu espaço (Cientista 10, trecho de entrevista concedida em 2015). Considerando que, como até o momento não existia nenhum regime internacional que impusesse restrições à exploração de combustíveis fósseis para limitar a extensão da mudança climática, essa narrativa defende que não faz sentido o Brasil abrir mão de suas grandes reservas petrolíferas.

Para a narrativa $\mathrm{B}$, o petróleo ainda representa um recurso energético de menor custo, maior excedente econômico, de alta disponibilidade e baixa entropia (Sauer, 2016) e cuja tendência é uma diminuição gradual (Schutte, 2013). Esse entendimento é compartilhado pelo cientista 7, para quem o Brasil não estaria indo na contramão da história ao investir no Présal, já que a transição para fontes de baixo carbono dificilmente acontecerá em um horizonte que torne a exploração do Pré-sal inviável (Cientista 7, trecho de documento do IPEA de 2012). Essa visão é respaldada por trabalhos que entendem que, mesmo com todos os esforços, a transição para fontes de energia mais renováveis levaria algumas décadas, pois, além de forte respaldo político, os combustíveis fósseis permanecem relativamente baratos, e são apoiados por uma infraestrutura muito ampla e duradoura (Chow; Kopp; Portney, 2003).

O Pré-sal é tratado nessa narrativa como produto e fomentador de pesquisa e desenvolvimento ${ }^{4}$ (Mancini; Paz, 2018; Gielfi, 2017), particularmente por meio da principal empresa brasileira do setor e a que mais investe em P\&D no país, a Petrobras (Gielfi, 2017). A narrativa coloca o setor petrolífero como uma mola propulsora do desenvolvimento pelo efeito multiplicador que exerce sobre outros setores industriais e de serviços (Piquet; Hasenclever; Shimoda, 2016).

${ }^{4} \mathrm{O}$ governo brasileiro introduziu uma cláusula contratual que obriga as companhias petrolíferas a investirem $1 \%$ da receita bruta de grandes campos petrolíferos em pesquisa e desenvolvimento (Mancini; Paz, 2018). 
Dentro de uma visão nacional desenvolvimentista, materializada num novo marco regulatório ${ }^{5}$, o Pré-sal é visto como um instrumento valioso na diminuição dos níveis de desigualdade social no país, e propulsor de um modelo de desenvolvimento próprio amparado na ciência e tecnologia (Heidrich; Haslam, 2016). Isso pode ser evidenciado pela afirmação do cientista 10, de que "a existência de uma reserva de pré-sal poderia financiar um plano nacional econômico e social e a Petrobras deveria ser contratada no regime de prestação de serviço" (Cientista 10, trecho de texto divulgado em O Globo em 2011), assim como pela do cientista 9, de que "a exploração do Pré-sal, desde que feita de modo racional e conforme os interesses nacionais, é indispensável para viabilizar o acesso de milhões de brasileiros a condições melhores de saúde, educação, cultura, moradia e saneamento" (Cientista 9, trecho de texto divulgado no site Brasil de Fato em 2014). Já para o cientista 6, "o Brasil deveria usar os recursos advindos da exploração do petróleo do Pré-sal para financiar a criação de um modelo de desenvolvimento único e autônomo, amparado em sólidos pilares de ciência e tecnologia, que favorecesse a exploração racional de seus próprios recursos naturais e de outras regiões tropicais" (trecho de texto divulgado na Agência Senado em 2009).

O Pré-sal não é visto aqui como um problema para a transição energética de baixo carbono. Para o cientista 10, "o enfrentamento das mudanças climáticas também exigirá posicionamento, com investimento em ciência e tecnologia para amenizar os impactos que a substituição energética terá na estrutura de produção e de consumo" (trecho de texto divulgado na Revista Carta Capital em 2011). Na perspectiva do Cientista 7, embora "pareça ser um desafio paradoxal: garantir que o pré-sal contribua para que o desenvolvimento no país englobe a transição para uma economia de baixo carbono", ele defende esse caminho a partir de "políticas claras e firmes, evitando ao máximo um crowding out do etanol e a instauração de uma cultura do desperdício" (trecho de texto divulgado em documento do IPEA, 2012). No entanto, é a terceira narrativa que enfatiza e aprofunda a relação causal entre o Pré-sal e a consolidação de uma transição energética menos intensiva em carbono.

${ }^{5}$ Em dezembro de 2010 foi sancionada a Lei no 12.351 que estabeleceu o regime de partilha da produção para áreas de Pré-sal e criou o Fundo Social. A partir disso, o país tem um regime regulador misto para o setor, que envolve concessão para as áreas fora do Pré-sal ou não consideradas estratégicas, e de partilha para o polígono definido em Lei. 


\section{Narrativa C: o Pré-sal como fomentador da transição energética para fontes de baixo carbono}

Os cientistas dessa narrativa entendem que a cadeia do petróleo ainda apresenta enormes economias de escala e escopo, com custos relativamente baixos em comparação com seus concorrentes e suportada por uma ampla e bem estabelecida infraestrutura. O Pré-sal é tratado como estratégico, tanto do ponto de vista da segurança quanto da transição energética. Para o cientista 16, "o petróleo, juntamente com o urânio, é imbatível em termos de energia estocada em um volume ínfimo e que ao mesmo tempo pode ser controlado (armazenado). Ainda que, em médio e longo prazo, a demanda por petróleo tenda a estagnar e depois declinar, seu banimento não parece possível" (trecho de texto divulgado no site da Revista Planeta em 2015).

Na perspectiva do cientista 12, as metas e alcances na redução das emissões em torno do desmatamento assumidas pelo Brasil, nos biomas da Amazônia e do Cerrado, permitirão o aumento das emissões do setor petrolífero sem comprometer os compromissos firmados pelo país (trecho de texto divulgado no site da Academia Brasileira de Direito em 2009).

No entanto, os cientistas desta narrativa defendem que parte da renda do Pré-sal seja destinada para a consolidação de um sistema energético menos intensivo em carbono, especificamente no desenvolvimento e disseminação de fontes de energia renovável, incluindo aquelas não tecnologicamente maduras e que exigem investimentos em capital reprodutível (Szklo; Schaeffer, 2006). Essa ideia é defendida pelo cientista 14 quando afirma que "com os recursos advindos da produção do petróleo do pré-sal, o Brasil poderá investir de forma consistente em programas tecnológicos para geração de energia 'limpa'. Isso nos permitirá ingressar de maneira mais robusta na fase pós-petróleo" (trecho de texto publicado em O Globo em 2009). Essa posição é reforçada também em artigo científico, cuja autoria é compartilhada pelos cientistas 13, 18 e 16: "devido à percepção de urgência da mudança climática, ao contrário da maioria das transições passadas, a transição para um regime baixo em carbono precisará ser deliberadamente gerenciada ou projetada. $\mathrm{O}$ uso de parte das rendas do petróleo pode ajudar a 'projetar essa transição'" (trecho de artigo científico publicado na revista Energy Policy em 2014; tradução nossa).

Essa narrativa defende o petróleo enquanto fomentador de sistemas de energia alternativos baseados em fontes renováveis, conforme entendimento 
dos cientistas 16 e 18. Para estes, por meio de suas infraestruturas consolidadas e do aprendizado tecnológico, é o petróleo que estabelece a escala necessária para a introdução de novas fontes de energia. Esse entendimento é colocado em artigo cuja autoria é compartilhada por alguns cientistas que reproduzem a narrativa $C$, no qual afirmam que: "é vital incluir o petróleo na 'equação dinâmica', descrevendo a transição para uma economia 'mais descarbonizada'. É vital garantir que as virtudes do petróleo deixem de ser barreiras para as fontes alternativas e se tornem agentes facilitadores dessas mesmas fontes alternativas" (trecho de artigo científico publicado na revista Energy em 2006; tradução nossa).

Esta narrativa destaca as "virtudes do petróleo" (Szklo; Schaeffer, 2006) como catalizadoras do processo de desenvolvimento e disseminação de fontes renováveis. Para o cientista 20, “o uso inteligente do Pré-sal é utilizar estes recursos para potencializar a transição para outra matriz energética, aproveitando as vantagens comparativas do Brasil em biomassa, solar, eólica, pequenas hidrelétricas" (Cientista 20, trecho de texto divulgado no Valor Econômico em 2009). Além dos recursos financeiros, o conhecimento científico e tecnológico desenvolvido para as condições geológicas extremas do Pré-sal brasileiro, principalmente na área de novos materiais e softwares, são tratados nessa narrativa como pilares importantes para a transição energética. Conforme a cientista 12, esse conhecimento e tecnologia "serve para outras coisas também, e você vai se desenvolvendo, vai criando capacidades que podem ser aplicadas em outras fontes energéticas, além da indústria de petróleo e gás" (Cientista 12, trecho de entrevista concedida em 2015).

Ao mesmo tempo, em curto prazo, a narrativa sugere a substituição de energias fósseis mais poluentes por outros fósseis de menor emissão de GEE. Nesse sentido, o gás natural das reservas do Pré-sal é colocado em destaque "como o mais limpo dos combustíveis fósseis" (Cientista 13, trecho de texto divulgado na Revista Pesquisa Fapesp em 2016), "que vai permitir a transição de um mundo mais carbono intensivo para um mundo menos carbono intensivo" (Cientista 18, em trecho de texto divulgado no site Pagina 22). Essa posição em relação ao gás natural tem sido defendida em um conjunto de trabalhos que apontam as potencialidades desse combustível na transição energética (McGlade et al., 2018; Vahl; Casarotto Filho, 2015; Santos et al., 2007). 
Essa narrativa apresenta uma posição atenuante ou paliativa para o problema climático, justificando também o próprio petróleo do Pré-sal como menos danoso ao clima que "as areias betuminosas do Canadá e o petróleo ultrapesado da Venezuela" (Cientista 13, trecho de texto divulgado na Folha de S. Paulo em 2009). Do mesmo modo, para o cientista 18, "se o Brasil exporta petróleo do Pré-sal, que é um petróleo bom, você até poderia dizer, sim, que o País está ajudando a reduzir as emissões no mundo" (Cientista 18, trecho de texto divulgado no site Pagina 22).

Quadro 2. Síntese das narrativas analisadas

\begin{tabular}{|l|l|}
\hline \multicolumn{2}{|c|}{ Narrativas científicas sobre o Pré-sal brasileiro } \\
\hline Agravante da mudança climática (Narrativa A) & $\begin{array}{l}\text { Imagem de um sistema próximo do colapso ou } \\
\text { do descontrole. Necessidade de ações preventivas } \\
\text { e de intervenção para deter ou retardar crise } \\
\text { iminente. História de declínio. Necessidade } \\
\text { de diminuição da exploração dessas reservas e } \\
\text { reversão dos investimentos energéticos em fontes } \\
\text { renováveis. Questionamento da perspectiva do } \\
\text { Pré-sal enquanto fator de redenção social e eixo } \\
\text { condutor do desenvolvimento nacional. Cientistas } \\
\text { afiliados a diferentes áreas de conhecimento. }\end{array}$ \\
\hline Eixo do desenvolvimento nacional & $\begin{array}{l}\text { Reconhecimento da problemática do clima e da } \\
\text { relação direta entre os combustíveis fósseis e o } \\
\text { aquecimento do planeta. Impacto, contribuição } \\
\text { e responsabilidade do Pré-sal para o problema é } \\
\text { questionado e relativizado frente aos potenciais } \\
\text { benefícios do empreendimento para o país. Setor } \\
\text { petrolífero é visto como uma mola propulsora } \\
\text { do desenvolvimento pelo efeito multiplicador } \\
\text { que exerce sobre outros setores industriais e de } \\
\text { baixo carbono (Narrativa C) }\end{array}$ \\
$\begin{array}{l}\text { serviços. Cientistas principalmente das áreas de } \\
\text { planejamento energético, relações internacionais } \\
\text { e ciências políticas. }\end{array}$ \\
\hline $\begin{array}{l}\text { As metas e alcances na redução das emissões em } \\
\text { torno do uso da terra permitirão o aumento das } \\
\text { emissões do setor petrolífero sem comprometer } \\
\text { os compromissos firmados pelo país. O Pré-sal } \\
\text { brasileiro é estratégico tanto do ponto de vista } \\
\text { da segurança, quanto da transição energética. Os } \\
\text { recursos financeiros, científicos e a infraestrutura já } \\
\text { consolidada do petróleo podem ser utilizados para } \\
\text { a disseminação de fontes renováveis. Perspectiva } \\
\text { atenuante, paliativa e gradual da transição } \\
\text { energética. Cientistas predominantemente da área } \\
\text { de planejamento energético. }\end{array}$ \\
\hline
\end{tabular}




\section{Narrativas científicas sobre o Pré-sal e processo decisório climático brasileiro}

Neste tópico, analisa-se a forma como os argumentos, ideias e perspectivas dessas três narrativas apareceram na Política Nacional de Mudanças Climáticas e na INDC brasileira apresentada na COP 21 em Paris.

\section{Política Nacional de Mudanças Climátıcas}

A PNMC, aprovada em 2009 (Lei no 12.187/09), formalizou os compromissos assumidos internacionalmente pelo país na COP 15 e se tornou o marco regulatório para as ações brasileiras de mitigação e adaptação (Motta, 2011). Ela estabeleceu a meta voluntária de redução de emissões de GEE entre 36,1\% e 38,9\% até 2020, baseada nas emissões de 2005, por meio de planos setoriais de mitigação (energético, agrícola e siderúrgico) e conservação de biomas, principalmente a Amazônia e o Cerrado (Rodrigues Filho et al., 2016). Para La Rovere e colaboradores (2014), o foco das ações de mitigatição na PNMC estava, sobretudo, voltado ao setor de uso da terra, especificamente no combate ao desmatamento da Floresta Amazônica.

A PNMC foi baseada no Plano Nacional de Mudanças Climáticas, resultado da articulação e mobilização do Fórum Brasileiro de Mudanças Climáticas, desde 2000 (Barbi, 2016). O governo federal vetou pontos na PNMC que traziam orientações e diretrizes em relação aos combustíveis fósseis. Por exemplo, foi excluído o inciso III do art. 4 que entendia que a PNMC visava ao "estímulo ao desenvolvimento e ao uso de tecnologias limpas e ao paulatino abandono do uso de fontes energéticas que utilizem combustíveis fósseis" (Brasil, 2009a). Também foi vetado o artigo 10 que versava sobre "a substituição gradativa dos combustíveis fósseis, como instrumento de ação governamental no âmbito da PNMC" (Brasil, 2009a). O Ministério de Minas e Energia justificou, em documento oficial, que a política energética do país já vinha priorizando a utilização de fontes de energia renováveis em sua matriz, o que tornava inadequada, segundo o então ministro, uma diretriz focada no abandono do uso de combustíveis fósseis (Brasil, 2009b).

Essas alterações na PNMC evidenciam que o governo buscou preservar o Pré-sal de compromissos e questionamentos em relação à questão climática. Essa interpretação é reforçada no Plano Decenal de Energia (PDE) de 2015, que é um instrumento da PNMC. Nesse PDE, cerca de 70\% dos recursos 
previstos (cerca de $\mathrm{R} \$ 1$ trilhão e meio de reais) para investimentos até 2025 estavam voltados à exploração e produção de fontes fósseis como petróleo e gás. Para o desenvolvimento de biocombustíveis, por exemplo, foram previstos em torno de 3\% desse total (EPE, 2015). Nesse sentido, o PDE é visto como um dos instrumentos mais refratários a ações efetivas que contribuam com reduções nas emissões de GEE dentro da PNMC (Neves; Chang; Pierri, 2015). A participação relativamente alta da energia renovável no sistema energético brasileiro, comparado à média de outros países, foi retradada pelo governo como demonstração efetiva da contribuição do Brasil, sendo o Pré-sal não prejudicial nesse sentido (Vieira; Dalgaard, 2013).

Para o presidente da Empresa de Pesquisa Energética (EPE) que assessorava o Ministério de Minas e Energia (MME) na área de estudos e pesquisas sobre planejamento energético entre 2004 e 2016, "não existe incompatibilidade do Pré-sal com a manutenção da matriz renovável" (trecho de texto divulgado no site Página 22, 2014). Ainda na sua concepção, e em consonância com as narrativas B e C, "todos os órgãos internacionais não apontam que o petróleo será substituído no curto prazo" (trecho de texto divulgado no site Página 22 em 2014).

O argumento e a preocupação da narrativa A - de que o Pré-sal seria um agravante do aquecimento global, independentemente de se o consumo desse petróleo ocorrer dentro ou fora do país - não foram considerados na PNMC com os vetos do governo em relação aos pontos que tratavam dos combustíveis fósseis. Para o governo brasileiro, como também evidenciado nas narrativas B e C, o Pré-sal não seria incompatível com os compromissos climáticos brasileiros, já que a maior parte do petróleo seria exportada, e mesmo as emissões adicionais do Pré-sal no país seriam compensadas por ações na área de uso do solo e energia renováveis. Portanto, assim como na Noruega (Down; Erickson, 2017), o Brasil sinaliza reduzir as emissões e limpar a sua própria contabilidade de carbono internamente, mas fazendo o oposto no exterior, considerando que a maior parte do petróleo do Présal seria voltada à exportação ${ }^{6}$.

Se existe uma sintonia entre os argumentos das narrativas B e C e os discursos e ações governamentais, não se pode dizer o mesmo em relação às expectativas destas narrativas quanto ao Pré-sal se constituir num eixo do desenvolvimento nacional e fomentador de energias renováveis. Em

${ }^{6} \mathrm{O}$ Petróleo ocupava, em 2017, o 3 o lugar no ranking das exportações brasileiras e movimentava cerca de US\$16,62 bilhões (Bernardes, 2018). 
termos de políticas sociais, os recursos do Fundo Social, por exemplo, não têm sido aplicados a contento em setores chaves como educação e saúde. Falhas e brechas na regulamentação desse fundo têm levado à aplicação dos recursos em outras finalidades (BBC Brasil, 2016), e à proposição de medidas no Congresso Nacional para reduzir a destinação de recursos para tais setores. Em 2018, uma das propostas em tramitação no Congresso pretendia retirar 20\% das receitas do Fundo Social do Pré-Sal destinadas a investimentos em saúde e educação, para subsidiar a expansão da rede de gasodutos do País (Warth, 2018; Ventura, 2018).

Embora o Fundo Nacional sobre Mudança do Clima (FNMC) ${ }^{7}$, enquanto instrumento da PNMC, tenha começado a utilizar os recursos provenientes do setor fóssil para apoio a projetos e estudos e financiamento de ações que visem à mitigação e à adaptação climática (Neves; Chang; Pierri, 2016), essa destinação foi prejudicada em 2012 com a aprovação do novo marco regulatório do Pré-sal. Uma parte dos recursos da participação especial ${ }^{8}$ na exploração de petróleo que era destinada ao FNMC acabou sendo destinada ao Fundo Social do Pré-sal. Desde 2012, o FNMC, que era o único mecanismo que previa a dotação de recursos petrolíferos para enfrentamento da mudança climática, não tem nenhuma previsão orçamentária seja do Fundo Social ou por qualquer fatia do orçamento da União.

Alguns trabalhos (Machado; Vilani, 2016; Viola; Franchini, 2013; Vieira; Dalgaard, 2013) sustentam que os altos investimentos do Brasil em combustíveis fósseis ilustram uma contradição entre a política energética e a retórica ambiental no processo de tomada de decisões do governo brasileiro. Para Viola e Franchini (2013), esse movimento já colocou certos limites à política externa brasileira em relação à transição para uma economia de baixo carbono, com a moderação da diplomacia do etanol desde o final de 2007.

${ }^{7} \mathrm{O}$ FNMC foi aprovado pela lei $12.114 / 2009$ e regulamentado pelo decreto $7.343 / 2010$. O FNMC tem como gestor técnico o Ministério de Meio Ambiente e, como agente financeiro, o Banco Nacional de Desenvolvimento Econômico e Social (BNDES).

${ }^{8}$ Participação especial na receita bruta nos casos de grande volume de produção, ou de grande rentabilidade, conforme definido pelo caput do artigo 50 da lei n. 9 9.478/97. 
Quadro 3. Síntese dos pontos centrais do governo brasileiro para a PNMC e conexões com as narrativas científicas analisadas

\begin{tabular}{|l|c|}
\hline \multicolumn{1}{|c|}{$\begin{array}{c}\text { Pontos centrais do governo brasileiro para a proposta } \\
\text { da PNMC }\end{array}$} & Narrativas científicas \\
\hline $\begin{array}{l}\text { Preservação da exploração e produção de petróleo do Pré-sal de } \\
\text { compromissos, restrições e questionamentos em relação à questão } \\
\text { climática }\end{array}$ & B, C \\
\hline $\begin{array}{l}\text { Brasil tem participação relativamente alta na matriz energética renovável } \\
\text { comparado à média de outros países }\end{array}$ & B \\
\hline $\begin{array}{l}\text { Não existe incompatibilidade do Pré-sal com a manutenção da matriz } \\
\text { renovável }\end{array}$ & B \\
\hline $\begin{array}{l}\text { Órgãos internacionais não apontam que o petróleo será substituído } \\
\text { no curto prazo }\end{array}$ & C \\
\hline $\begin{array}{l}\text { Pré-sal não seria incompatível com agenda climática, já que a maior } \\
\text { parte do petróleo seria exportada e as emissões nacionais seriam } \\
\text { compensadas por ações na área de uso do solo e energia renováveis }\end{array}$ & B, C \\
\hline $\begin{array}{l}\text { Utilização da renda do petróleo para promoção de fontes renováveis } \\
\text { no país }\end{array}$ & \\
\hline
\end{tabular}

Fonte: Elaboração dos autores.

\section{COP-21 E INDC BRASILEIRA}

O Acordo de Paris, firmado ao final da COP-21, marca um novo modelo de contribuição dos países, não mais com imposição de metas, mas com contribuições voluntárias, sendo que cada país indicou sua iNDC com base nas suas capacidades domésticas (Victor, 2016). A iNDC brasileira propõe a redução de 37\% de GEE em 2025 e de 43\% de redução em 2030, em comparação com os valores de 2005 (Itamaraty, 2015). A contribuição brasileira estabelece algumas diretrizes: aumento do uso de biocombustíveis, desmatamento ilegal zero, restauração e reflorestamento de 12 milhões de hectares, participação de 45\% de energias renováveis na matriz energética, aumento da participação de fonte eólica, solar e biomassa, alcance de 10\% de eficiência energética, e fortalecer a agricultura de baixa emissão, todos até o ano de 2030 (Itamaraty, 2015). 
Reis e colaboradores (2017) entendem que agricultura e ecossistemas ainda são os principais eixos estruturantes da iNDC proposta pelo Brasil, mesmo com uma mudança nas emissões entre 2005 e 2014. Em 2005, o setor de uso do solo foi responsável por 58\% das emissões nacionais. Entretanto, as emissões do setor de uso da terra diminuíram significativamente, atingindo 19\% do total de emissões em 2014. Essa redução nas emissões deveu-se principalmente à redução do desmatamento na Amazônia desde 2004. Já as emissões de outros setores de atividade aumentaram nesse período. Energia e agricultura foram os setores que tiveram o maior aumento nas emissões de 2005 a 2012. Em 2014, as emissões do setor de energia, por exemplo, representaram $36 \%$ do total.

Um dos estudos que embasaram a iNDC brasileira na COP-21, intitulado "Implicações econômicas e sociais de cenários de mitigação de gases de efeito estufa no Brasil até 2030-IES-Brasil" (La Rovere et al., 2016), envolvendo trinta cientistas brasileiros, aponta que as ações voltadas ao desmatamento seriam ainda o principal eixo que iria permitir ao país cumprir os objetivos de redução das emissões em 2020. O estudo considerou, em seus cenários futuros de emissões, a expansão da extração de óleo bruto no país de 167\% entre 2010 e 2030, atingindo a marca de 5,5 milhões de barris por dia ( $\mathrm{Mbbl} / \mathrm{dia})$. Assumiu-se, dentro da perspectiva das narrativas $\mathrm{B}$ e C, que a maior parte do volume extraído (57\% em 2030) seria destinada à exportação e, consequentemente, não comprometendo as metas de redução de emissão no país.

Diante desse quadro, algumas análises (Araújo; Leite, 2016; Lucon et al., 2016) sugerem que, mesmo com as intenções de expansão dos biocombustíveis na sua INDC, o Brasil tem se tornado mais intensivo em carbono, e não menos, devido ao aumento da dependência de combustíveis fósseis e investimentos pesados nos campos de petróleo do Pré-Sal. Além disso, tem tomado decisões contraditórias à sua iNDC. Em 2015, por exemplo, o governo cortou do plano plurianual de investimentos para 2016-2019 a inclusão da expansão da geração de energia solar e eólica e aumentou subsídios para a indústria de petróleo (Araújo; Leite, 2016). Outro exemplo nesse sentido foi a aprovação da Lei no 13.586 de 2017, que prevê uma série de subsídios por 20 anos para petrolíferas estrangeiras que atuam no país e para a estatal Petrobras. O Congresso Nacional já havia aprovado, em 2016, a Lei 13.365/2016, que revogou a obrigatoriedade da participação da Petrobras como única operadora na exploração do 
petróleo do Pré-sal. Essa mudança abriu caminho para acelerar o ritmo de investimentos estrangeiros no setor e elevar a participação de outras gigantes petroleiras na produção de petróleo e gás no Brasil (Alvarenga, 2016). Essa é outra decisão que frustra as expectativas de cientistas das narrativas B e C. Para o cientista 15, "a mudança enfraquece a Petrobras e retira a prioridade do Brasil no desenvolvimento de tecnologia para a exploração de águas profundas" (Cientista 15, trecho de texto divulgado no Portal G1, 2016).

Após a apresentação da iNDC brasileira, mesmo as ações de combate ao desmatamento, que eram o principal carro chefe do país no campo da mitigação, vêm sofrendo ameaças num contexto de crise e instabilidade política. Rochedo et al. (2018) argumentam que o abandono das políticas de controle do desmatamento e o apoio político às práticas agrícolas predatórias, por exemplo, têm colocado em risco a contribuição do Brasil para o Acordo de Paris. O novo quadro político nacional também traz novas incertezas e ameaças no campo da diplomacia climática e nos compromissos assumidos pelo país nesse tema. Marcado por um discurso anti-ambientalista, o atual governo recusou-se a sediar a COP-25 e se manifestou a favor da retirada do país do Acordo de Paris, caso fira a soberania nacional (Klein; Rosas, 2018).

Quadro 4. Síntese dos pontos centrais do governo brasileiro para a iNDC e conexões com as narrativas científicas analisadas

\begin{tabular}{|c|c|}
\hline $\begin{array}{l}\text { Pontos centrais do governo brasileiro para a proposta } \\
\text { da INDC }\end{array}$ & Narrativas científicas \\
\hline $\begin{array}{l}\text { Preservação da exploração e produção de petróleo das metas e ações } \\
\text { de mitigação do país }\end{array}$ & $\mathrm{B}, \mathrm{C}$ \\
\hline $\begin{array}{l}\text { Aumento do uso de biocombustíveis e energias renováveis sem } \\
\text { diminuição da exploração e exportação do petróleo }\end{array}$ & $B, C$ \\
\hline $\begin{array}{l}\text { Desmatamento ilegal zero, restauração e reflorestamento são pontos } \\
\text { centrais para a mitigação }\end{array}$ & $\mathrm{C}$ \\
\hline Fortalecimento da agricultura de baixa emissão & - \\
\hline $\begin{array}{l}\text { Permanência e intensificação da produção petrolífera no país nas } \\
\text { próximas décadas }\end{array}$ & B \\
\hline
\end{tabular}




\section{Considerações finais}

$\mathrm{Na}$ arena científica brasileira, e sobretudo entre o grupo de cientistas analisado neste artigo, o debate sobre a mudança climática não está pautado e nem restrito às posições dicotômicas entre céticos e aquecimentistas. Contudo, o prevalecente consenso sobre o problema foi substituído por divergências em torno das ações de mitigação no país. Num contexto nacional marcado pela existência de grandes reservas petrolíferas e por seu real peso político, social, econômico e tecnológico, a amplitude de disciplinas, visões e abordagens científicas contribuiu para o surgimento de diferentes narrativas científicas sobre o papel do petróleo num contexto de mudança climática e de transição energética.

Diferentemente de visões que mostram que os cientistas tendem a estar associados a frames que destacam problemas e suas causas, enquanto os políticos e gestores a frames que enfatizam julgamentos e soluções (Trumbo, 1996), as três narrativas científicas analisadas evidenciam tanto interpretações causais quanto expectativas e proposições sobre petróleo e mudança do clima. Nessas narrativas, combinam-se tanto elementos factuais quanto subjetivos, tais como o otimismo individual, enredos dramáticos, símbolos, esperança, orgulho nacional e incerteza (Sovacool; Brossmann, 2013). Se, para a narrativa A, os benefícios globais gerados com a redução da extração de petróleo no Brasil são concretos e diretos para minimizar o problema climático global, para as narrativas $\mathrm{B}$ e $\mathrm{C}$ isso não é claro e certo. Além disso, para essas duas últimas narrativas, a utilização do Pré-sal é justificada com base na contínua demanda por petróleo, na inexistência de restrições legais e políticas para o uso dessa fonte, na possibilidade de os recursos gerados serem empregados em políticas sociais, científicas e tecnológicas e, ainda, de servirem como uma alavanca para a transição energética.

Portanto, as narrativas analisadas evidenciam a multidimensionalidade e complexidade das questões energética e climática, especificamente em relação ao papel e uso de petróleo em países com grandes reservas deste recurso, como é caso brasileiro. Contudo, essas narrativas também contribuíram para embasar e justificar decisões governamentais voltadas para o aumento da disponibilidade de petróleo no mercado global. Tais decisões dificultam a diminuição do peso dos combustíveis fósseis na matriz energética global a médio prazo, colocando em cheque os acordos climáticos 
internacionais de não ultrapassar o aumento de $1,5^{\circ} \mathrm{C}$ na temperatura média global.

Das três narrativas científicas tratadas, as narrativas B e C apresentaram maior proximidade e entrelaçamento com as decisões do governo brasileiro, na COP-15 e COP-21, de proteger o Pré-sal de questionamentos, imposições e compromissos de ordem climática e de concentrar suas ações de mitigação, principalmente no setor de uso e ocupação da terra. Nesse sentido, não é possível falar, portanto, numa desconexão entre ciência e política em relação às decisões que levaram à intensificação da produção petrolífera no Brasil com o Pré-sal. Entretanto, as expectativas e prescrições presentes e constituintes das narrativas $\mathrm{B}$ e $\mathrm{C}$ em relação ao Pré-sal (de este constituir-se num indutor de desenvolvimento nacional e de transição energética) não se concretizaram até o momento e defrontam-se com limites e incertezas para o futuro. Cabe destacar, ainda, que mesmo o combate ao desmatamento, principal foco das propostas empreendidas pelo Brasil, sobretudo na iNDC, encontra-se ameaçado com a nova correlação de forças no executivo federal resistente à questão climática. O Brasil, visto anteriormente como um importante ator global na mitigação, pode reverter drasticamente seu papel.

Por fim, do ponto de vista teórico-metodológico, o artigo evidencia e reforça a relevância da abordagem de narrativas científicas para compreensão do processo de policy making e das interfaces entre ciência e política em torno de questões controversas e multifacetadas, como é o caso da mudança climática.

\section{Agradecimentos}

Os autores agradecem os financiamentos da Fapesp (Proc. 2013/05930-6) e CNPq (Proc. 446032/2015-8). 
José Eduardo Viglio é Doutor em Ciências Sociais e pesquisador colaborador no Núcleo de Estudos e Pesquisas Ambientais (Nepam) da Universidade Estadual de Campinas.

Đeduviglio@gmail.com

Gabriela Marques Di Giulio é Doutora em Ambiente e Sociedade, professora do Departamento de Saúde Ambiental da Faculdade de Saúde Pública da Universidade de São Paulo. ggiulio@usp.br

Fabiana Barbi é Doutora em Ambiente e Sociedade e pesquisadora colaboradora no Nepam, Universidade Estadual de Campinas.

$\risingdotseq$ fabarbi@gmail.com

Lúcia da Costa Ferreira é Doutora em Ciências Sociais e orientadora nos Programas de Doutorado em Ambiente e Sociedade e Ciências Sociais da Universidade Estadual de Campinas.

Đluciacf@unicamp.br

\section{Referências}

1. ALTHOR, Glenn; WATSON, James E. M. ; FULLER, Richard A. Global mismatch between greenhouse gas emissions and the burden of climate change. Scientific reports, v. 6, Id 20281, 2016. doi: 10.1038/srep20281

2. ALVARENGA, Darlan. Mudança no pré-sal abre espaço para avanço estrangeiro na exploração. G1, 10 nov. 2016. Disponível em: < http://g1.globo.com/economia/ noticia/2016/11/mudanca-no-pre-sal-abre-espaco-para-avanco-estrangeiro-naexploracao.html $>$.

3. ANDERSON, Alison. Media, politics and climate change: towards a new research agenda. Sociology Compass, v. 3, n. 2, p. 166-182, 2009. doi: 10.1111/j.17519020.2008.00188.x.

4. ARAÚJO, Suely M.V.G.; LEITE, Henrique P.S. The Brazilian Intended National Determined Contribution (INDC) and energy policy. Brazilian Center for International Relations, edição especial, v. 1, ano 15, 2016.

5. BARBI, Fabiana. Governing climate change in China and Brazil: mitigation strategies. Journal of Chinese Political Science, v. 21, n. 3, p. 357-370, 2016. doi: 10.1007/s11366-016-9418-y.

6. BARDIN, Laurence. L'analyse de contenu. Paris: Presses Universitaires de France, 1977.

7. BBC BRASIL. Por que os recursos do pré-sal estão frustrando o setor da educação. BBC News, 20 jan. 2016. Disponível em: <https://www.bbc.com/ portuguese/noticias/2016/01/160104_royalties_educacao_pai >. 
8. BEATTY, John. Narrative possibility and narrative explanation. Studies in History and Philosophy of Science - Part A, v. 62, p. 31-41, 2017. doi: 10.1016/j. shpsa.2017.03.001.

9. BERNARDES, Flávio. De cada US\$ 100 que o Brasil embolsou em 2017, mais de US\$ 40 vieram do agro. Gazeta do Povo, 3 jan. 2018. Disponível em <https://www.gazetadopovo.com.br/agronegocio/mercado/de-cadaus-100-que-o-brasil-embolsou-em-2017-mais-de-us-40-vieram-do-agro3qkxguxeokhobo1p2lyvo13fv/>.

10. BRASIL 2009a. Lei №. Lei no 12.187, de 29 de dezembro de 2009. Institui a Política Nacional sobre Mudança do Clima-PNMC e dá outras providências. Diário Oficial da República Federativa do Brasil, Brasília, DF, v. 29, 2009.

11. BRASIL 2009b. Mensagem no 1.123, de 29 de dezembro de 2009. Brasília: Presidência da República, 2009. Disponível em: <http://www.planalto.gov.br/ ccivil_03/_ato2007-2010/2009/msg/vep-1123-09.htm>. Acesso: Janeiro de 2019.

12. CHOW, Jeffrey; KOPP, Raymond J.; PORTNEY, Paul R. Energy resources and global development. Science, v. 302, n. 5650, p. 1528-1531, 2003. doi: 10.1126/ science.1091939

13. COOK, John et al. Quantifying the consensus on anthropogenic global warming in the scientific literature. Environmental Research Letters, v. 8, n. 2, p. 024024, 2013. doi: 10.1088/1748-9326/8/2/024024.

14. CURRIE, Adrian; STERELNY, Kim. In defence of story-telling. Studies in History and Philosophy of Science - Part A, v. 62, p. 14-21, 2017. doi: 10.1016/j. shpsa.2017.03.003.

15. DAHLSTROM, Michael F. Using narratives and storytelling to communicate science with nonexpert audiences. Proceedings of the National Academy of Sciences, v. 111, n. Supplement 4, p. 13614-13620, 2014. doi: 10.1073/ pnas. 1320645111.

16. DOWN, Adrian; ERICKSON, Peter. Norwegian oil production and keeping global warming 'well below $2^{\circ} \mathbf{C}^{\prime}$. SEl discussion brief. Estocolmo: Stockholm Environment Institute, 2017.

17. DOWNS, Julie S. Prescriptive scientific narratives for communicating usable science. Proceedings of the National Academy of Sciences, v. 111, n. Supplement 4, p. 13627-13633, 2014. doi: 10.1073/pnas.1317502111.

18. ENTMAN, Robert M. Projections of power: framing news, public opinion, and US foreign policy. Chicago: University of Chicago Press, 2004.

19. EPE - Empresa de Pesquisa Energética. Plano Decenal de Expansão de Energia 2024. Brasília: Ministério de Minas e Energia - Empresa de Pesquisa Energética, 2015. Disponível em: <http://www.epe.gov.br/PDEE/Relat\%C3\%B3rio\%20 Final\%20do\%20PDE\%202024.pdf > .

20. FERREIRA, Lúcia da C. Dimensões humanas da biodiversidade: mudanças sociais e conflitos em torno de áreas protegidas no Vale do Ribeira, SP, Brasil. 
Ambiente \& Sociedade, v. 7, n. 1, p. 47-66, 2004. doi: 10.1590/S1414753X2004000100004.

21. FERREIRA, Lúcia da C. A equação dinâmica entre conflitos sociais, recursos naturais e desastres ambientais: o estado da arte e uma proposta teórica. In: VI Encontro da Associação Nacional de Pós-Graduação e Pesquisa em Ambiente e Sociedade Anais [...], Belém: ANPPAS, 2012.

22. FERREIRA, Lúcia da C. et al. Conflictos entre expansión urbana y cobertura vegetal y sus consecuencias para los cambios ambientales globales: un estudio en el Titoral del Estado de São Paulo, Brasil. In: FERREIRA, Lúcia da C.; SCHIMIDT, Luísa; BUENDIA, Mercedes P.; CALVIMONTES, Jorge; VIGLIO, José E. Clima de tensão: ação humana, biodiversidade e mudanças climáticas. Campinas: Editora da Unicamp, 2017.

23. FORRESTER, John. Thinking in cases. Cambridge: Polity Press, 2017.

24. GABRIEL, Yiannis. The narrative veil: truth and untruths in storytelling. In: GABRIEL, Yiannis (Ed.). Myths, stories, and organizations: premodern narratives for our times. Oxford: Oxford University Press, 2004, p. 17-31.

25. GEELS, Frank W. Regime resistance against low-carbon transitions: introducing politics and power into the multi-level perspective. Theory, Culture \& Society, v. 31, n. 5, p. 21-40, 2014. doi: 10.1177/0263276414531627.

26. GIELFI, Giovanna G. A interação universidade-empresa na indústria de petróleo brasileira. 2017. Tese (Doutorado em Política Científica e Tecnológica) - Instituto de Geociências, Universidade Estadual de Campinas, Campinas, 2017.

27. HAJER, Maarten A.; HOPPE, Robert; JENNINGS, Bruce. The argumentative turn in policy analysis and planning. Durham: Duke University Press, 1993.

28. HANNIGAN, John. Environmental sociology. Nova York: Routledge, 2014.

29. HEIDRICH, Pablo; HASLAM, Paul A. From neoliberalism to resource nationalism: states, firms and development. In: HASLAM, Paul A.; HEIDRICH, Pablo (Eds.). The political economy of natural resources and development. Nova York: Routledge, 2016. p. 23-54.

30. HERMAN, David. Narrative ways of worldmaking. In: HEINEN, Sandra; SOMMER, Roy (Eds.). Narratology in the age of cross-disciplinary narrative research, 2009, p. 71-87.

31. HERMWILLE, Lukas. The role of narratives in socio-technical transitions Fukushima and the energy regimes of Japan, Germany, and the United Kingdom. Energy Research \& Social Science, v. 11, p. 237-246, 2016. doi: 10.1016/j. erss.2015.11.001.

32. HILGARTNER, Stephen; BOSK, Charles L. The rise and fall of social problems: a public arenas model. American Journal of Sociology, v. 94, n. 1, p. 53-78, 1988.

33. HOEGH-GULDBERG, Ove et al. Coral reefs under rapid climate change and ocean acidification. Science, v. 318, n. 5857, p. 1737-1742, 2007. doi: 10.1126/ science. 1152509 . 
34. ITAMARATY. Pretendida contribuição nacionalmente determinada (iNDC) para a consecução do objetivo da Convenção-Quadro das Nações Unidas sobre mudança do clima. Brasília: República Federativa do Brasil, 2015. Disponível em: <http://www.itamaraty.gov.br/images/ed_desenvsust/BRASILiNDC-portugues.pdf $>$.

35. JANG, S. Mo; HART, P. Sol. Polarized frames on "climate change" and "global warming" across countries and states: evidence from twitter big data. Global Environmental Change, v. 32, p. 11-17, 2015. doi: 10.1016/j. gloenvcha.2015.02.010.

36. JASANOFF, Sheila; WYNNE, Brian. Science and decisionmaking. In: RAYNER, Steve; MALONE, Elizabeth L. (Eds.). Human choice \& climate change: the societal framework. v. 1. Columbus: Batelle Press, 1998, p. 1-87.

37. JENKINS-SMITH, Hank C.; SABATIER, Paul A. The study of public policy processes. In: SABATIER, Paul A.; JENKINS-SMITH, Hank C. (Eds.). Policy change and learning: an advocacy coalition approach. Boulder: Westview Press, 1993, p. 1-9.

38. JONES, Cleveland M.; CHAVES, Hernani AF. Assessment of yet-to-find-oil in the Pre-Salt area of Brazil. In: 14th International Congress of the Brazilian Geophysical Society \& EXPOGEF, Rio de Janeiro, Brazil, 3-6 August 2015. Brazilian Geophysical Society, 2015. p. 7-12.

39. KEATS, Patrice A. Multiple text analysis in narrative research: visual, written, and spoken stories of experience. Qualitative Research, v. 9, n. 2, p. 181-195, 2009. doi: 10.1177/1468794108099320.

40. KELLER, Ann C. Science in environmental policy: the politics of objective advice. Cambridge: MIT Press, 2009.

41. KLEIN, Cristian; ROSAS, Rafael. Bolsonaro ameaça deixar Acordo de Paris se mudanças não forem feitas. Valor Econômico, 12 dez. 2018. Disponível em: < https://www.valor.com.br/politica/6023525/bolsonaro-ameaca-deixar-acordode-paris-se-mudancas-nao-forem-feitas $>$.

42. KLINSKY, Sonja et al. Why equity is fundamental in climate change policy research. Global Environmental Change, v. 44, p. 170-173, 2017. doi: 10.1016/j. gloenvcha.2016.08.002.

43. LA ROVERE, Emilio L. et al. Implicações econômicas e sociais de cenários de mitigação de gases de efeito estufa no Brasil até 2030. In: Fórum Brasileiro de Mudanças Climáticas - FBMC. Sumário Técnico [...] COPPE/UFRJ, Rio de Janeiro, 2016.

44. LA ROVERE, Emilio L.; PEREIRAJR., Amaro O.; DUBEUX, Carolina B. S.; WILLS, William. Climate change mitigation actions in Brazil. Climate and Development, v. 6, n. sup1, p. 25-33, 2014. doi: 10.1080/17565529.2013.812952.

45. LAWTON, John H. Ecology, politics and policy. Journal of Applied Ecology, v. 44, n. 3, p. 465-474, 2007. doi: 10.1111/j.1365-2664.2007.01315.x. 
46. LAWTON, Ricky N.; RUDD, Murray A. A narrative policy approach to environmental conservation. Ambio, v. 43, n. 7, p. 849-857, 2014. doi: 10.1007/ s13280-014-0497-8.

47. LEFÉVRE, Julien; WILLS, William; HOURCADE, Jean-Charles. Combining low-carbon economic development and oil exploration in Brazil? An energyeconomy assessment. Climate Policy, v. 18, n. 10, p. 1286-1295, 2018. doi: 10.1080/14693062.2018.1431198.

48. LUCON, Oswaldo et al. Oportunidades e desafios para aumentar sinergias entre as políticas climáticas e energéticas no Brasil. Opções de políticas para reduzir emissões relacionadas ao uso de energia. Relatório. Word Resource Institute e Instituto de Energia e Ambiente - Universidade de São Paulo, São Paulo, 2016. Disponível em: <https://wribrasil.org.br/pt/publicacoes/oportunidades-desafiosaumentar-sinergias-politicas-climaticas-energeticas-no-brasil $>$.

49. MACHADO, Carlos J. S.; VILANI, Rodrigo M. From environmental information to precaution in the face of environmental risks: an analysis of Brazil's National Policy on Climate Change and rulings by higher courts. In: LÉNA, Philippe; ISSBERNER, Liz-Rejane. Anthropocene in Brazil: an inquiry into development obsession and policy limits. Nova York: Routledge, 2016, p. 212-219.

50. MANCINI, Lorenzo; PAZ, María José. Oil sector and technological development: effects of the mandatory research and development (R\&D) investment clause on oil companies in Brazil. Resources Policy, v. 58, p. 131-143, 2018. doi: 10.1016/j.resourpol.2018.04.006.

51. MATSUURA, Sérgio. Brasil ganha 'prêmio' Fóssil do Dia por propor subsídios de R\$1 tri para petróleo. O Globo, 16 nov. 2017. Disponível em: <https://oglobo. globo.com/sociedade/ciencia/meio-ambiente/brasil-ganha-premio-fossil-do-diapor-propor-subsidios-de-1-tri-para-petroleo-22073458>.

52. MCGLADE, Christophe; EKINS, Paul. The geographical distribution of fossil fuels unused when limiting global warming to 2 C. Nature, v. 517, n. 7533, p. 187, 8 jan. 2015.

53. MCGLADE, Christophe; PYE, Steve; EKINS, Paul; BRADSHAW, Michael; WATSON, Jim. The future role of natural gas in the UK: a bridge to nowhere? Energy Policy, v. 113, p. 454-465, 2018. doi: 10.1016/j.enpol.2017.11.022.

54. MCNEIL, Ben I.; MATEAR, Richard J. Southern Ocean acidification: a tipping point at 450-ppm atmospheric CO2. Proceedings of the National Academy of Sciences, v. 105, n. 48, p. 18860-18864, 2008. doi: 10.1073/pnas.0806318105.

55. MONTEIRO, Marko S.A. Reconsiderando a etnografia da ciência e da tecnologia. Tecnociência na prática. Revista Brasileira de Ciências Sociais, v. 27, n. 79, p. 139-151, 2012. doi: 10.1590/S0102-69092012000200009.

56. MORGAN, Mary S.; WISE, Norton M. Narrative science and narrative knowing. Introduction to special issue on narrative science. Studies in History and Philosophy of Science Part A, v. 62, p. 1-5, 2017. doi: 10.1016/j. shpsa.2017.03.005. 
57. MOTTA, Ronaldo S. da. A política nacional sobre mudança do clima: aspectos regulatórios e de governança. In: MOTTA, Ronaldo S. da et al. Mudança do clima no Brasil: aspectos econômicos, sociais e regulatórios. Brasília: Ipea, 2011.

58. NEVES, Frederico M.; CHANG, Manyú; PIERRI, Naína. As estratégias de enfrentamento das mudanças climáticas expressas nas políticas públicas federais do Brasil. Desenvolvimento e Meio Ambiente, v. 34, 2015. doi: 10.5380/dma. v34i0.37739.

59. NISBET, Matthew C. Communicating climate change: why frames matter for public engagement. Environment: Science and Policy for Sustainable Development, v. 51, n. 2, p. 12-23, 2009. doi: 10.3200/ENVT.51.2.12-23.

60. OSTROM, Elinor. Nested externalities and polycentric institutions: must we wait for global solutions to climate change before taking actions at other scales?. Economic Theory, v. 49, n. 2, p. 353-369, 2012. doi: 10.1007/s00199-0100558-6.

61. PIQUET, Rosélia P.; HASENCLEVER, Lia; SHIMODA, Eduardo. O desenvolvimento e a política de conteúdo local na indústria petrolífera: visões divergentes. Revista Tecnologia e Sociedade, v. 12, n. 24, p. 45-58, 2016. doi: 10.3895/rts.v12n24.3194.

62. PREVIDI, Michael et al. Climate sensitivity in the Anthropocene. Quarterly Journal of the Royal Meteorological Society, v. 139, n. 674, p. 1121-1131, 2013.

63. RAFTERY, Adrian E.; ZIMMER, Alec; FRIERSON, Dargan M.W.; STARTZ, Richard; LIU, Peiran. Less than 2 C warming by 2100 unlikely. Nature Climate Change, v. 7, n. 9, p. 637-641, 2017. doi: 10.1038/nclimate3352.

64. REIS, Tiago et al. Desafios e oportunidades para avançar as Contribuições Nacionais no setor agropecuário e de florestas na América Latina: o caso do Brasil.

Relatório de pesquisa. Belém: Instituto de Pesquisa Ambiental da Amazônia, 2017. Disponível em: <http://ipam.org.br/wp-content/uploads/2017/04/PCL IPAM.pdf?fbclid=IwAR3DRdXnM6IY_HNHWFLv3Y0Nql4g-THtzu6ZQ1txAVaEĀ LDSQ3Up826PoHM>.

65. RENN Ortiwn. The social arena concept of risk debates. In: KRIMSKY, Sheldon; GOLDING, Dominic (Orgs.). Social Theories of Risk. Westport: Praeger, 1992, p. 179-196.

66. ROCHEDO, Pedro R.R. et al. The threat of political bargaining to climate mitigation in Brazil. Nature Climate Change, v. 8, n. 8, p. 695-698, 2018. doi: 10.1038/s41558-018-0213-y.

67. RODRIGUES FILHO, Saulo; LINDOSO, Diogo P.; BURSZTYN, Marcel; NASCIMENTO, Carolina G. O clima em transe: políticas de mitigação e adaptação no Brasil. Revista Brasileira de Climatologia, v. 19, p. 74-90, 2016. doi: http:// dx.doi.org/10.5380/abclima.v19i0.48874.

68. ROE, Emery. Narrative policy analysis: theory and practice. Durham: Duke University Press, 1994.

69. SANTOS, Edmilson M. dos; FAGA, Murilo T.W.; BARUFI, Clara B.; POULALLION, Paul L. Gás natural: a construção de uma nova civilização. 
Estudos Avançados, v. 21, n. 59, p. 67-90, 2007. doi: 10.1590/S010340142007000100007.

70. SAUER, Ildo L. O pré-sal e a geopolítica e hegemonia do petróleo face às mudanças climáticas e à transição energética. In: MELFI, Adolpho, J.; MISI, Aroldo; CAMPOS, Diogenes de A.; CORDANI, Umberto G. (Orgs.). Recursos Minerais do Brasil. Rio de Janeiro: Academia Brasileira de Ciências, 2016. p. 308-322.

71. SCHUTTE, Giorgio R. Brazil: new developmentalism and the management of offshore oil wealth. European Review of Latin American and Caribbean Studies/ Revista Europea de Estudios Latinoamericanos y del Caribe, n. 95, p. 49-70, 2013. doi: 10.18352/erlacs.9230.

72. SETO, Karen C. et al. Carbon lock-in: types, causes, and policy implications. Annual Review of Environment and Resources, v. 41, p. 425-452, 2016. doi: 10.1146/annurev-environ-110615-085934.

73. SHANAHAN, Elizabeth A.; JONES, Michael D.; MCBETH, Mark K. Policy narratives and policy processes. Policy Studies Journal, v. 39, n. 3, p. 535-561, 2011. doi: 10.1111/j.1541-0072.2011.00420.x.

74. SINGH, Shane P.; SWANSON, Meili. How issue frames shape beliefs about the importance of climate change policy across ideological and partisan groups. PloS one, v. 12, n. 7, p. e0181401, 2017. doi: 10.1371/journal.pone.0181401.

75. SOVACOOL, Benjamin K.; BROSSMANN, Brent. Fantastic futures and three American energy transitions. Science as Culture, v. 22, n. 2, p. 204-212, 2013.

76. SPENCE, Alexa; PIDGEON, Nick. Framing and communicating climate change: The effects of distance and outcome frame manipulations. Global Environmental Change, v. 20, n. 4, p. 656-667, 2010. doi: 10.1016/j.gloenvcha.2010.07.002.

77. STONE, Deborah A. Causal stories and the formation of policy agendas. Political Science Quarterly, v. 104, n. 2, p. 281-300, 1989. doi: 10.2307/2151585.

78. STONE, Deborah A. Policy paradox: the art of political decision making. Nova York: WW Norton, 1997.

79. SZKLO, Alexandre; SCHAEFFER, Roberto. Alternative energy sources or integrated alternative energy systems? Oil as a modern lance of Peleus for the energy transition. Energy, v. 31, n. 14, p. 2513-2522, 2006. doi: 10.1016/j. energy.2005.11.001.

80. TODD, John; DE CARVALHO, Benjamin. Brazil-A New Global Energy Player and Partner for the EU?. In: EU Leadership in Energy and Environmental Governance. Palgrave Macmillan, London, 2016. p. 181-202.

81. TRUMBO, Craig. Constructing climate change: claims and frames in US news coverage of an environmental issue. Public Understanding of Science, v. 5, p. 269-283, 1996. doi: 10.1088/0963-6625/5/3/006.

82. UNRUH, Gregory C. Understanding carbon lock-in. Energy Policy, v. 28, n. 12, p. 817-830, 2000. doi: 10.1016/S0301-4215(00)00070-7. 
83. VAHL, Fabricio P.; CASAROTTO FILHO, Nelson. Energy transition and path creation for natural gas in the Brazilian electricity mix. Journal of Cleaner Production, v. 86, p. 221-229, 2015. doi: 10.1016/j.jclepro.2014.08.033.

84. VAN BOMMEL, Séverine; VAN DER ZOUWEN, Mariëlle. Creating scientific narratives: experiences in constructing and interweaving empirical and theoretical plots. In: ARTS, Bas; BEHAGEL, Jelle; VAN BOMMEL, Séverine; KONING, Jessica de; TURNHOUT, Esther (Eds.). Forest and Nature Governance. A practice based approach. Dordrecht: Springer, 2012. p. 217-239.

85. VENTURA, Manoel. Recurso do Pré-sal poderá ir para ampliação de gasoduto. O Globo, 10 nov. 2018. Disponível em: <https://oglobo.globo.com/economia/ recurso-do-pre-sal-pode-ir-para-ampliacao-de-gasoduto-23226308>.

86. VICTOR, David G. Making the promise of Paris a reality. In: STAVINS, Robert N.; STOWE, Robert C. (Eds.). The Paris agreement and beyond: international climate change policy post-2020. Cambridge: Harvard Project on Climate Agreements, 2016.

87. VIEIRA, Marco A.; DALGAARD, Klaus G. The energy-security-climate-change nexus in Brazil. Environmental Politics, v. 22, n. 4, p. 610-626, 2013. doi: 10.1080/09644016.2013.806633.

88. VIOLA, Eduardo; FRANCHINI, Matías. Brasil na governança global do clima, 2005-2012: a luta entre conservadores e reformistas. Contexto Internacional, v. 35, n. 1, p. 43-76, 2013. doi: 10.1590/S0102-85292013000100002.

89. VON MEIER, Alexandra; MILLER, Jennifer L.; KELLER, Ann C. The disposition of excess weapons plutonium: a comparison of three narrative contexts. The Nonproliferation Review, v. 5, n. 2, p. 20-31, 1998.

90. WARTH, Anne. Projeto coloca recursos da saúde e educação em gasodutos. O Estado de São Paulo, 7 maio 2018. Disponível em: < https://economia. estadao.com.br/noticias/geral, projeto-coloca-recursos-da-saude-e-educacao-emgasodutos,70002299093>. 